\title{
1 Abstract
}

2 Objective: The purpose of this study is to compare postoperative pain scores between children

3 undergoing tonsillectomy and adenoidectomy (T\&A) surgery and their parents, identify potential

4 predictors for this disagreement, and determine possible impact on analgesic administration.

5 Methods: This is a prospective longitudinal study conducted with children undergoing outpatient

6 T\&A in 4 major tertiary hospitals and their parents. Children and their parents were enrolled prior

7 to surgery and completed baseline psychological instruments assessing parental anxiety (STAI),

8 parental coping style (MBSS), child temperament (EAS) and parental medication administration

9 attitude questionnaire (MAQ). Postoperatively, parents and children completed at-home pain

10 severity ratings (Faces Pain Scale-Revised, children; Numeric Rating Scale, parents) on

11 postoperative recovery days 1,2 , and 3 , reflecting an overall pain level for the past 24 hours.

12 Parents also completed a log of analgesic administration. Based on postoperative pain scores,

13 parent-child dyads were classified as overestimators (i.e., parents rated their child's pain higher

14 than children rated their own pain), in agreement (i.e., rating in agreement), or underestimators

15 (i.e., parents rated their child's pain lower than children rated their own pain).

16 Results: A significant proportion of parent-child pairs disagreed on pain ratings on postoperative

17 days 1-3 (30.05\%-35.95\%). Of those pairs in disagreement, the majority of parents overestimated

18 their child's pain on all three postoperative days, specifically such that a total of $24-26 \%$ parents

19 overestimated their child's pain on postoperative days 1, 2, and 3. Repeated measures ANOVA

20 demonstrated that parents in the overestimator group administered higher, though still within safe

21 limits, amounts of ibuprofen and oxycodone (mg/day) than did the underestimator or agreement

22 groups. Multiple regression models showed hospital site as the only independent predictor for

23 postoperative pain rating disagreement between children and parents. 
24 Conclusions: Since parents overestimate their child's postoperative pain and may administer more 25 analgesics to their child, it is essential to develop a standardized method of child pain assessment 26 and a tailored recommended postoperative analgesic regimen amongst medical providers for 27 children undergoing T\&A. 


\section{Introduction}

Research indicates that up to $75 \%$ of all children undergoing surgery in the United States experience significant postoperative pain.[1] A large proportion of these children suffer from pain

31 following discharge from the hospital in the home recovery phase.[2-8] In addition to the hardship

32 associated with this clinical phenomenon, children who suffer from significant postoperative pain

33 are more likely to experience delayed behavioral and clinical recovery.[2,9-11]

It is well established that successful management of postoperative pain requires both

35 reliable assessment of pain levels, as well as administration of the right analgesics in the right

36 dosage and at the right time.[12-16] Within home settings, parents are most often responsible for

37 managing their child's pain following surgery $[9,10]$ and as such, parental assessment of child pain

38 along with child assessment is of high significance. Previous research revealed conflicting results

39 regarding agreement of pain ratings between parent-child dyads. [11,14,17-19] These previous

40 studies suffer from a number of methodological flaws and have focused on describing pain rating

41 disagreement and not predictors or clinical impact of such disagreement. We submit that assessing

42 the impact of disagreement on actual clinical practice is of paramount importance and, if it is

43 discovered that such a disagreement does not have any impact on clinical care or outcomes, then

44 pain rating discrepancies between parents and children are less significant. In contrast, if such

45 disagreement has clinical impact, it is highly important to identify predictors for such 46 disagreement.

47 The primary aim of this study was to compare postoperative pain assessment between 48 children and their parents in a population of children undergoing tonsillectomy and adenoidectomy

49 (T\&A), given this procedure is one of the most common pediatric surgeries and has been found to 50 be associated with high levels of postoperative pain.[12,20,21] The study's secondary aims were 
51 to determine if any disagreement found had clinical impact in terms of analgesic administration by

52 parents and to identify potential predictors for any disagreement found between children and 53 parents.

54 


\section{Materials and Methods}

\subsection{Participants}

This prospective longitudinal 5-year study was funded by the Eunice Kennedy Shriver National Institute of Child Health and Human Development (NICHD) and was conducted from 2012 to 2017 . The study included children undergoing outpatient T\&A surgery and their parents and was aimed at evaluating a newly developed behavioral intervention that targeted reduction of preoperative anxiety in children. This 5-year study consisted of: 1) a baseline phase which lasted 2.5 years and consisted of only data collection (no intervention), and 2) an intervention phase which lasted 2.5 years and included implementation of the intervention which was detailed previously. [22]

For the purpose of the current manuscript, we analyzed data only from the baseline phase of the study and not any data following the intervention. Also, none of the analyses and data presented in this manuscript have been published previously. [23]

Children enrolled in the 5-year study underwent surgery at Children's Hospital of Los Angeles; Lucile Packard Children's Hospital at Stanford; Children's Hospital, Denver; and Children's Hospital of Orange County. The average annual number of outpatient T\&A surgeries performed at each of these institutions was 523, 480, 1151, and 774, respectively. Children adhered to the following criteria: 2-15 years old, an American Society of Anesthesiologists (ASA) physical health status of I-III, and English- and/or Spanish-speaking. Exclusion criteria included children with chronic illness that puts them in ASA IV (extreme systemic disorders which have already become an eminent threat to life regardless of the type of treatment), developmental delays as diagnosed by primary pediatrician, or born prematurely $(<32$ weeks gestational age). Children admitted overnight were excluded from the study. These exclusion criteria were implemented 
78 because children with cognitive impairments may present different responses and emotions to

79 stressors of surgery. The institutional review board at each of the four sites approved the study,

80 and informed consent and age appropriate assent were acquired from parent and child at each site.

81 Of the 1,315 eligible patients for the 5-year study, 402 declined to participate and 86

82 consented but later withdrew their consent to participate. A total of 827 parent-child dyads

83 completed the 2.5-year baseline phase. As some of the patients in the baseline phase did not report

84 their postoperative pain, only a total of 311 parent-child dyads are included in the analysis of this

85 manuscript. Because of variability in responses across postoperative days, our final sample size is

86306,287 , and 203 dyads for postoperative ratings on days 1, 2, and 3, respectively.

\section{$87 \quad 2.2$ Measures}

$88 \quad 2.21$ Pain Assessment Measures:

\subsection{Child:}

90 Child self-reported pain was measured using the Faces Pain Scale-Revised (FPS-R), which

91 consists of a series of six faces ranging from a neutral expression ("no pain") to an expression

92 of "most pain possible".[24] The FPS-R has demonstrated good convergent validity to a linear

93 interval scale of observational ratings of pain,[24] excellent reliability, and is recommended

94 for use with children 4 to 18 years old.[25,26]

\subsection{Parents:}

96 Parents used the Numeric Rating Scale (NRS) to rate children's postoperative pain on a 0 to

9710 point scale. The NRS has been found to be valid, reliable, and favored by patients for its 98 high sensitivity.[27] Furthermore, prior research has found the NRS and FPS-R as functionally 99 equivalent.[16,28]

$100 \quad 2.22$ Psychological Measures 
102 The EAS-TS is a parent-reported measure of children's temperament from early childhood to 103 adolescence in emotionality, activity, sociality, and shyness. Parents use a Likert-type scale to 104 rate their child on 20 statements reflecting temperament. We selected the EAS-TS given that 105 child temperament predicts child's response to pain,[30] and this survey has demonstrated both 106 strong validity across temperament measures and high test-retest reliability.[29]

$107 \quad 2.222$ Medication Attitudes Questionnaire (MAQ)

108 Parents completed the self-report MAQ, which characterizes attitudes on the use of analgesics 109 to treat children's pain. The MAQ is comprised of 27 items rated on a Likert-type scale, which 110 characterize parent beliefs on three subscales: Appropriate Use (e.g., "Children learn how to 111 use pain medication responsibly when it is given for pain"), Side Effects (e.g., "There is little 112 need to worry about side effects from pain medication"), and Avoidance (e.g., "Pain medication 113 works best when it is given as little as possible").[10] Previous findings have reported the 114 MAQ to have an overall internal consistency between 0.68 and 0.73 , as determined by 115 Cronbach's Alpha.[31]

$116 \quad 2.223$ State-Trait Anxiety Inventory (STAI)[32]

117 Parent anxiety was measured using the STAI, a self-report assessment which assesses the state 118 (situational) and trait (baseline) anxiety using 20 items on a 4-point scale. The STAI-state 119 anxiety assesses respondents on how they feel at the present time, while the STAI-trait anxiety 120 assesses respondent on how they "generally" feel. Higher scores on both state- and trait-STAI 121 tests correspond to higher levels of anxiety. This measure has shown high test-retest 122 correlations, which range from 0.73 to 0.86 .[32]

$123 \quad 2.224$ Miller Behavioral Style Scale (MBSS) [33] 
Parental coping style was measured using the MBSS, a parent self-report form with strong

125 validity and reliability,[33] that presents respondents with four stressful scenarios and eight

126 possible reactions to each scenario, instructing the respondent to indicate which reaction(s)

127 they would most likely display. Respondents are characterized on two behavioral styles:

128 monitoring (high monitoring--information seeking, low monitoring-information avoiding),

129 and blunting (high blunter-distractors, low blunter-non-distractors).

$130 \quad \underline{2.23 \text { Demographic Measures }}$

131 Baseline demographics were collected for each parent-child dyad, including child gender,

132 ethnicity and race of child and parent, and primary language spoken at home.

\section{$133 \quad 2.3$ Procedures}

134 The day before surgery, potential participants were identified using surgery schedules and 135 determined for eligibility based on electronic medical record pre-screening. During the patient's 136 pre-surgical appointment, or on the day of surgery, researchers approached potential participants

137 in clinic or within the preoperative holding area, respectfully. After gaining consent and 138 confirming eligibility, parents and children were provided with study information documents. On

139 the day of surgery, parents completed a demographics questionnaire including gender, age, race

140 and ethnicity, education, income, etc., and several psychological surveys (MAQ, EAS-TS, STAI,

141 MBSS). These measures were completed while parents were in the preoperative holding area 142 before surgery or waiting area as their children underwent surgery. At the end of each day on 143 postoperative days 1, 2, and 3, parents completed the NRS and administered the FPS-R to their 144 child to reflect the child's overall pain level for the past 24 hours. In addition, parents documented 145 all analgesics administered to children on each of these assessment days using a questionnaire later 146 submitted to the research team. Documentation included date and time of administration, type of 
147 analgesic given (ultimately decided upon by the parent), and dosage in whichever method the 148 analgesic was given (tablet, teaspoon, $\mathrm{cc} / \mathrm{mL}$, droppers, etc). If more than one analgesic was 149 administered, parents provided these same data parameters for each analgesic.

All clinical personnel were instructed not to change any of their standard management of

151 the patients as this was the observational longitudinal phase of the 5-year study. As such, 152 preoperative sedative premedication, parental presence during induction of anesthesia, as well as 153 the surgical, anesthetic, and analgesic course were all managed based on preferences of individual

154 anesthesiologists and surgeons. Following surgery, children were moved to the post-anesthesia 155 care unit (PACU) and subsequently met by their parents. The PACU nurse then explained 156 discharge instructions and provided directions for at-home postoperative pain management to the 157 parent and child. Instructions for pain management varied by the four hospital sites and are 158 described in Table 1. The case surgeon then returned to meet the families and provided a surgical 159 summary, answered questions, and authorized the child's discharge. Pain throughout the entire 160 perioperative period was managed per standard of care of each of the four hospitals and the 161 anesthesiologist and surgeon managing the case.

\section{$162 \quad 2.4$ Statistical Analyses}

163 Normally distributed continuous data are presented in this manuscript as means \pm standard

164 deviation; skewed continuous data are presented as medians (interquartile range); and categorical 165 data are presented as proportions. Data were analyzed with SPSS software (version 22.0; IBM, 166 Armonk, NY, USA), and $P<0.05$ was used to determine statistical significance.

167 To determine parent-child agreement in pain ratings, we first calculated the differences in 168 pain rating between parents and children using the child FPS-R (consisting of six faces which were 169 scored 0 - no pain to 10 -maximum pain, with intervals of 2 points between each face) and the 
170 parent NRS (recorded on a 0-10 scale). Since pain reporting data was not normally distributed, a

171 Wilcoxon Signed Ranks Test was used to determine disagreement between median parent and

172 child postoperative pain ratings on each of the follow up assessment days.[34]

173 Next, we calculated the percentage of dyads who demonstrated significant disagreement

174 between postoperative pain ratings. Previous research has identified that a difference of $20 \%$ -

$17535 \%$ in pain rating corresponds to a meaningful decrease in pain intensity.[35,36] As such, we

176 determined a priori that disagreement in this study between the score of the child and the score of

177 the parent will be defined as a difference of 2 or more points on the standardized $0-10$ pain rating

178 scale. Once we identified which parent-child dyads were in disagreement on each of the three

179 postoperative days, all parent-child dyads included in the study were categorized into one of 3

180 groups: parents who overestimated their child's pain (OE), parents whose pain ratings were in

181 agreement with child ratings (A), and parents who underestimated their child's pain (UE).

182 Due to instances in which a parent-child dyad was inconsistent in their ratings across the 183 three postoperative days (that is, the parent may have overestimated their child's pain on one of 184 the postoperative days, and been in agreement or underestimated on another one of the days), we 185 decided that parents had to overestimate, be in agreement, or underestimate their child's pain on 186 at least two of the three postoperative days to be classified in one of the three groups. This 187 methodology eliminated 56 dyads who were inconsistent in their pain rating classifications across 188 postoperative days. These dyads were not included in the subsequent bivariate analysis to identify 189 predictors of disagreement, or in comparisons of analgesic administration between groups.

190 Analgesic administration, which accounted for both type and dosage administered by 191 parent to their child (in milligram per kilogram), was examined within each of the three groups.

192 Statistical differences of various analgesics administered over time were calculated using repeated 
193 measures analysis of variance (ANOVA), where $\mathrm{T} 1=$ postoperative day $1, \mathrm{~T} 2=$ postoperative day

1942 , and $\mathrm{T} 3=$ postoperative day 3 , and the three groups in question were overestimators (OE), 195 agreement (A), and underestimators (UE).

196 The next phase of statistical analyses determined whether any of the collected demographic 197 and psychological variables predicted parent-child postoperative pain disagreement. Demographic 198 variables in question included: child gender, race-ethnicity, and age; parent education and race199 ethnicity; family marital status, household income, whether the child had undergone previous 200 surgery, child anxiety at previous medical visits, and pain level that parents expected their child to 201 endure during the current procedure. Psychological variables included the EAS-TS, MAQ, STAI, 202 and MBSS. Using the three subgroups of dyads (OE, A, UE), a chi-square calculation was 203 performed for categorical variables and a one-way ANOVA was performed for continuous 204 variables to identify potential correlations between predictor variables and postoperative pain 205 rating agreement. Results of these analyses were used to compute logistic regression models to 206 examine the relation between dyad groups and possible predictive variables, as well as to control 207 for potential confounding variables. 


\section{Results}

A total of 311 parent-child dyads were included in this study. The reader is referred to

211 Table 2 for a full description of the various demographic characteristics of the population reported

212 in this manuscript. Participants primarily consisted of male children $(50.2 \%)$ with a mean age of 6

$213 \pm 3$ years, parent respondents were primarily mothers $(85.2 \%)$, and English was the primarily

214 language (74.0\%).

\subsection{Do parents and child disagree when assessing postoperative pain?}

218 child FPS-R median scores ( $p$ 's $<0.05$, Table 3 ). Using the previously defined criterion (2-points)

219 for clinically significant disagreement between parent and child pain ratings, we found that a large 220 proportion of parent-child dyads were in disagreement on postoperative day 1, 110/306 (35.95\%), 221 day 2, 102/287 (35.54\%), and day 3, 61/203 (30.05\%) (Fig. 1). When looking only at dyads who 222 were in disagreement, in 79/110 (71.82\%) of the dyads, parents overestimated on day 1 ; in $75 / 102$ $223(73.52 \%)$ of the dyads, parents overestimated on day 2 ; and in 49/61 (80.33\%) of the dyads, parents 224 overestimated on day 3.

\subsection{What is the clinical impact of the disagreement between parents and children?}

228 postoperative administration of ibuprofen both across time (T1, T2, T3) and group (OE, A, UE).

229 This analysis did not reveal a significant difference within groups across time $(\mathrm{T} 1-3, p=0.575)$,

230 however it did reveal borderline statistical differences across groups $(p=0.074)$. A between group

231 post-hoc analysis indicated that parents in the OE group administered more ibuprofen than did 232 parents in the A group on day $2(p=0.013)$ and day $3(p=0.047)$. 
A second two-way repeated measures ANOVA was conducted for oxycodone and included

234 only postoperative days 1 and 2 given the sample size of children who used this medication on day

2353 was in the single digits. We found statistically significant differences both over time $(p=0.001)$

236 and between groups $(p=0.000)$. Post-hoc between groups analysis revealed that administration of

237 oxycodone was higher in the OE group than the A group on day $1(p=0.037)$ and day $2(p=$ $2380.004)$

239 Next, we ran three individual repeated measures ANOVA tests for acetaminophen, 240 hydrocodone, and codeine consumption over days 1, 2, and 3. We found that for all these three 241 medications there was a decrease of total amount given per day as a function of the postoperative 242 day $(p=0.001)$, but that there were no group (OE, A, UE) differences for these medications.

\subsection{Is it possible to predict which parent-child dyad will be in disagreement?}

246 variables and a one-way ANOVA for continuous variables to identify potential predictors of

247 disagreement. As can be seen in Table 4, anxiety of the child at previous medical visits $(p=0.012)$

248 and hospital site of the study $(p=0.005)$ emerged as clinically different between the three study

249 groups. There were no other differences identified between the 3 groups for all other variables 250 tested $(p=\mathrm{ns})$.

251 In order to control for potentially confounding variables, we next conducted logistic 252 regression models utilizing the previously identified potential predictors. Two sets of logistic 253 regression models were performed to evaluate hospital site as a predictor of group assignments.

254 The first model used hospital site to predict whether parents were more likely to underestimate or 255 agree with their child (overall significance, $p=0.210$ ), and the second used hospital site to predict 256 whether parents were more likely to overestimate or agree with their child (overall significance, $p$ 
$257=0.002$ ). Table 5 depicts the distribution of group assignments across all hospital sites on each of 258 the three postoperative days in question. Table 6 indicates, hospital site was found to be the only 259 independent predictor for group assignment of the dyads. Specifically, overall parents were more 260 likely 5.7 times more likely to overestimate than agree with their child's pain at Lucile Packard 261 Children's Hospital as compared to Children's Hospital, Denver $(\beta=1.749, p=0.001, O R=5.750$, $26295 \% C I=2.108-15.687)$. An additional logistic regression model determined that anxiety of the

263 child at previous medical visits was not a significant predictor of group assignment $(p=0.164)$.

264 Table 7 conveys the breakdown of socioeconomic data at each of the hospital sites used to compute 265 the logistic regression model. 


\section{Discussion}

The goals of the study were to identify if there is disagreement on pain rating between children

268 undergoing surgery and their parents, as well to examine if we can predict those parents and

269 children who disagreed and to examine the potential impact of this disagreement on the

270 administration of analgesics. Under the conditions of this study, we found that a significant

271 proportion of parents and children were in disagreement in determining the children's

272 postoperative pain severity in the first 3 days after surgery. Of parent-child dyads in disagreement,

273 most parents overestimated their child's pain, and those parents were more likely to administer

274 more ibuprofen and oxycodone during the postoperative course. Multiple regression models

275 showed hospital site as the sole independent predictor for postoperative pain rating disagreement.

276 Postoperative pain management is a critical factor in recovery after surgery. After

277 discharge from the hospital, parents are mostly responsible for managing their child's

278 postoperative pain. As evident in the postoperative medication instructions (Table 1), each of the

279 four sites included in this manuscript provided parents with individualized instructions for at-home

280 analgesic administration. This could be one explanation for the finding that parents at Stanford

281 were significantly more likely to overestimate their child's pain as compared to parents at other

282 sites. That is, if parents at Stanford were instructed to administer pain medication around the clock,

283 they may have interpreted this as an indication that their child should be experiencing pain and

284 would require more medication. This could potentially lead to parent-child pain rating

285 disagreement, which is supported by previous findings which have shown that parents often

286 experience difficulty in accurately identifying their child's pain level and determining the proper

287 amount of analgesics to relieve the pain. $[19,37,38]$ It is interesting to note that the present study

288 did not identify socioeconomic status (neither in family income, nor in parental education) as 
predictors of disagreement. This finding may even further emphasize the need for providing

290 parents highly specific instructions on postoperative pain management, for parents do not

291 necessarily rely on their own education or knowledge-base in identifying and treating their child's

292 pain. Table 7 highlights the distribution of education levels and incomes of parent-child dyads

293 amongst the four hospital sites.

294 If parents are provided a way of interpreting their child's postoperative pain, with analgesic

295 instructions that correspond to appropriate pain levels, it could mean that a more specific means

296 of identifying postoperative at-home pain levels may be imperative in reducing parent-child pain

297 rating disagreement. Previous research on parent management of child's postoperative pain at

298 home has found that 79 percent of parents found a supportive phone call to clarify instructions on

299 postoperative pain management was useful.[15] Further, current practice in most institutions

300 typically devotes more time on directions of how to assess pain and how to manage pain in the

301 PACU, rather than in the pre-surgical visit. Since parents are highly stressed on the day of surgery,

302 it is no wonder that many parents simply don't comprehend or remember these instructions from

303 the PACU. A better solution would be to provide more information preoperatively or use mobile

304 Health (mHealth) as a supportive tool.[39,40]

305 Analyses of pain medication administration found that overestimator parents provided

306 significantly more ibuprofen and oxycodone on some postoperative days than those dyads in

307 agreement. This is the first study in this area that has documented that parental overestimation of

308 pain can result, in some cases, in higher administration of analgesics by parents. Although the

309 average quantity of analgesics administered by overestimator parents was still within safe limits,

310 it is important to recognize that since the child's pain is less than assumed by the parent, it can

311 likely be treated by a lower dosage of analgesics. By recognizing appropriate pain levels and 
312 administering the appropriate amount of analgesics, there is greater likelihood of avoiding higher-

313 administration, which, if severe, may result in acetaminophen-induced liver toxicity,[41] codeine-

314 associated nausea, dizziness, vomiting, and fatalities,[42] and ibuprofen-related gastric discomfort

315 or vomiting.[43] The results of this report should also be viewed within the context of the ongoing

316 debate on the opioid epidemic and the role of pain management in that epidemic. The finding that

317 hospital site was a predictor of disagreement, and that postoperative analgesic instructions varied

318 by site highlights the critical importance of providing a clear methodology of assessing and treating

319 a child's postoperative pain, as well as clear expectations on the amount of pain that should be

320 expected. We believe, that these elements of clear instructions as well as clear expectations could

321 be used to combat the opioid epidemic within the context of postoperative pain

322 Future studies should seek to provide refined postoperative pain management instructions.

323 most postoperative pain management instructions required parents to provide analgesics "as

324 needed" based on their child's pain (Table 1), and our findings demonstrate significant

325 disagreement in parent-child postoperative pain ratings, there is great risk of parents

326 misinterpreting their child's pain, and therefore, providing inaccurate analgesic dosages.

327 The present study did not include highly sensitive measures to identify the impact of

328 ethnicity, but it is important to note that previous literature has shown that parental perioperative

329 anxiety and stress can be impacted by variables such as ethnicity, language, and acculturation.[23]

330 Such, it would be helpful to explore the role of these variables in affecting parental vigilance when

331 evaluating postoperative pain.

332 Though the present study did not find age to be a predictor of dyad disagreement, the data

333 showed that children of UE parents were older, on average, than children of A or OE parents (Table

334 4). This corresponds to previous literature which has shown that older children may experience 
more pain, as well as increased analgesic use and delayed return to day-to-day functioning than

336 younger children following T\&A surgery.[44,45] Since UE dyads were of higher age, on average,

337 it is worthwhile to provide specific instructions to parents of older children on potentially higher

338 pain rates. Ultimately, is of most critical importance to provide concrete directions to all parents

339 on identifying and treating child postoperative pain.

340 The results of this study should be interpreted with caution because of a number of 341 methodological limitations. We did not consider the operative surgeon, surgical technique,

342 anesthesiologist, and anesthetic techniques that all have a bearing on postoperative pain, but should

343 not affect the proportion of OE, A, and UE dyads. In the analysis of analgesics administered, we

344 did not consider the combination of codeine and acetaminophen as a separate group or those

345 patients who alternated acetaminophen with ibuprofen. Indeed, we analyzed the data for each drug

346 for the entire group, and this was done because of the small sample size of both the alternating

347 group and the combination group. The results analyzed also depend on the reliability of parents in 348 correctly recording analgesic administration, as this was not witnessed/verified by any additional

349 parties. In addition, there was substantial loss to follow-up over time, such that 306 dyads reported 350 data for postoperative day 1, as compared to 203 dyads on day 3. This drop off can be expected, 351 as parents may not be as inclined to continue recording data if the child is recovering and returning 352 to baseline function. These methodological limitations aside, we should note that this is the first 353 publication of its kind that not only describes the phenomena of disagreement in pain scores 354 between children and their parents, but also looks at the impact of these scores on analgesic 355 consumption as well as trying to identify predictors for this phenomena.

356 Conclusively, the present manuscript provides evidence that a significant portion of parent357 child dyads are in disagreement on children's postoperative pain ratings. Of dyads in disagreement, 
358 the majority of parents overestimated their child's pain and provided substantially more analgesics 359 to their child during postoperative recovery at home. Given the substantial number of children 360 suffering from postoperative pain during home recovery, as well as the negative implications of 361 postoperative pain and overmedication, it is crucial to improve postoperative pain management at 362 home. This could be done by establishing a universal protocol used throughout hospitals on how 363 to use a pain scale in assessing child pain and tailoring pain medications based on the pain score. 


\section{References}

366 [1] H. Owen, V. McMillan, D. Rogowski, Postoperative pain therapy: a survey of patients' expectations and their experiences, Pain. 41 (1990) 303-307.

[2] M.A. Fortier, J. Chou, E.L. Maurer, Z.N. Kain, Acute to chronic postoperative pain in children: Preliminary findings, J. Pediatr. Surg. 46 (2011). doi:10.1016/j.jpedsurg.2011.03.074.

[3] G.A. Finley, P.J. McGrath, S.P. Forward, G. McNeill, P. Fitzgerald, Anonymous, Parents' management of children's pain following “minor" surgery, Pain. 64 (1996) 83-87. http://www.sciencedirect.com/science?_ob=MImg\&_imagekey=B6T0K-3VXJK3J-8Br J Anaesth. 82 (1999) 886-889.

[5] V. Unsworth, L.S. Franck, I. Choonara, Parental assessment and management of children's postoperative pain: a randomized clinical trial, J Child Heal. Care. 11 (2007) 186-194.

[6] F.F. Warnock, J. Lander, Pain progression, intensity and outcomes following tonsillectomy, Pain. 75 (1998) 37-45. http://www.sciencedirect.com/science?_ob=MImg\&_imagekey=B6T0K-3S66M0N-4C\&_cdi $=4865 \& \_u s e r=4422 \& \_p i i=S 0304395997002029 \& \_$origin $=$gateway\&_coverDate $=$ 03/31/1998\&_sk=999249998\&view $=c \& w c h p=d G L b V l b-$ zSkzV\&md5=384910c69561695e17172948e0aa2491\&ie=/sdarticle.pdf. 
388 [7] S.A. Wiggins, R.L. Foster, Pain after tonsillectomy and adenoidectomy: "ouch it did hurt bad,” Pain Manag Nurs. 8 (2007) 156-165.

390 [8] M.E. Wilson, H.L. Helgadottir, Patterns of pain and analgesic use in 3- to 7-year-old children after tonsillectomy, Pain Manag Nurs. 7 (2006) 159-166.

392 [9] V. Gedaly-Duff, D. Ziebarth, Anonymous, Mothers' management of adenoidtonsillectomy pain in 4- to 8-year-olds: a preliminary study, Pain. 57 (1994) 293-299.

[10] S. Forward, T.L. Brown, P.J. McGrath, Mothers' attitudes and behavior toward medicating children's pain, Pain. 67 (1996) 469-474.

[11] H. Zhou, P. Roberts, L. Horgan, Association between self-report pain ratings of child and parent, child and nurse and parent and nurse dyads: meta-analysis, J. Adv. Nurs. 63 (2008) 334-342.

[12] M.A. Fortier, J. Chou, E.L. Maurer, Z.N. Kain, Acute to chronic postoperative pain in children: preliminary findings, J Pediatr Surg. 46 (2011) 1700-1705. doi:S00223468(11)00289-2 [pii] 10.1016/j.jpedsurg.2011.03.074.

[13] M.A. Fortier, J.E. MacLaren, S.R. Martin, D. Perret, Z.N. Kain, Pediatric pain after ambulatory surgery: Where's the medication?, Pediatrics. 124 (2009) e588-95. doi:10.1542/peds.2008-3529.

[14] C.T. Chambers, G.J. Reid, K.D. Craig, P.J. McGrath, G.A. Finley, Agreement between child and parent reports of pain, Clin J Pain. 14 (1998) 336-342. http://www.ncbi.nlm.nih.gov/entrez/query.fcgi?cmd=Retrieve\&db=PubMed\&dopt=Citati on\&list_uids=9874013.

[15] D.A. Jonas, Parent's management of their child's pain in the home following day surgery., J. Child Health Care. 7 (2003) 150-62. http://www.ncbi.nlm.nih.gov/pubmed/14516009 
(accessed July 1, 2016).

[16] C. von Baeyer, L. Spagrud, J. McCormick, E. Choo, K. Neville, M. Connelly, Three new datasets supporting use of the Numerical Rating Scale (NRS-11) for children's self-reports of pain intensity., Pain. 143 (2009) 233-7. doi:10.1016/j.pain.2009.03.002.

[17] M.H. Bellman, C.E. Paley, Pain control in children. Parents underestimate children's pain., BMJ. 307 (1993) 1563. http://www.ncbi.nlm.nih.gov/pubmed/8274939 (accessed July 11, 2016).

[18] U. Rajasagaram, D.M. Taylor, G. Braitberg, J.P. Pearsell, B.A. Capp, Paediatric pain assessment: Differences between triage nurse, child and parent, J. Paediatr. Child Health.

[19] R.S. Greenberg, C. Billett, M. Zahurak, M. Yaster, R.S. Greenberg, C. Billett, M. Zahurak, M. Yaster, Videotape increases parental knowledge about pediatric pain management, Anesth. Analg. 89 (1999) 899-903.

[20] A.K. Tan, J. Rothstein, T.L. Tewfik, Anonymous, Ambulatory tonsillectomy and adenoidectomy: complications and associated factors, J. Otolaryngol. 22 (1993) 442-446. 99-101. Pediatric Inductions with an Empirically Based Intervention, Anesthesiology. 115 (2011) 18-27. doi:10.1097/ALN.0b013e3182207bf5.

[23] R.S. Stevenson, A. Rosales, M.A. Fortier, B. Campos, B. Golianu, J. Zuk, J. Gold, Z.N. Kain, The Role of Ethnicity and Acculturation in Preoperative Distress in Parents of 
Children Undergoing Surgery., J. Immigr. Minor. Health. (2016) [Epub ahead of print].

435

436

437

438

439

440

441

442

443

444

445

446

447

448

449

450

451

452

453

454

455

456 doi:10.1007/s10903-016-0357-7.

[24] C.L. Hicks, C.L. von Baeyer, P.A. Spafford, I. van Korlaar, B. Goodenough, The Faces Pain Scale-Revised: toward a common metric in pediatric pain measurement, Pain. 93 (2001) 173-183. http://www.sciencedirect.com/science?_ob=MImg\&_imagekey=B6T0K439VCON-C-

1R\&_cdi=4865\&_user=4422\&_pii $=$ S0304395901003141\&_origin=gateway\&_coverDate $=08 / 31 / 2001 \& \_s k=999069997 \& v i e w=c \& w c h p=d G L b V t z-$ zSkzV\&md5=ba45b7332e3232d792c6389f5170f57c\&ie=/sdarticle.pdf.

[25] P.J. McGrath, G.A. Walco, D.C. Turk, R.H. Dworkin, M.T. Brown, K. Davidson, C. Eccleston, G.A. Finley, K. Goldschneider, L. Haverkos, S.H. Hertz, G. Ljungman, T. Palermo, B.A. Rappaport, T. Rhodes, N. Schechter, J. Scott, N. Sethna, O.K. Svensson, J. Stinson, C.L. von Baeyer, L. Walker, S. Weisman, R.E. White, A. Zajicek, L.K. Zeltzer, Core Outcome Domains and Measures for Pediatric Acute and Chronic/Recurrent Pain Clinical Trials: PedIMMPACT Recommendations, J. Pain. 9 (2008) 771-783. doi:DOI: 10.1016/j.jpain.2008.04.007.

[26] G. Garra, A.J. Singer, B.R. Taira, J. Chohan, H. Cardoz, E. Chisena, H.C. Thode, Validation of the Wong-Baker FACES pain rating scale in pediatric emergency department patients, Acad. Emerg. Med. 17 (2010) 50-54. doi:10.1111/j.15532712.2009.00620.x.

[27] A. Williamson, B. Hoggart, Pain: a review of three commonly used pain rating scales., J. Clin. Nurs. 14 (2005) 798-804. doi:10.1111/j.1365-2702.2005.01121.x.

[28] J. Miro, E. Castarlenas, A. Huguet, Evidence for the use of a numerical rating scale to 
assess the intensity of pediatric pain., Eur. J. Pain. 13 (2009) 1089-95. doi:10.1016/j.ejpain.2009.07.002.

[29] A.H. Buss, R. Plomin, Theory and Measurement of EAS, in: R. Plomin (Ed.), Temperament Early Dev. Personal. Trait., L. Erlbaum Associates, New Jersey, Hillsdale, 1984: pp. 98-130.

[30] N.L. Schechter, B.A. Bernstein, A. Beck, L. Hart, L. Scherzer, Individual differences in children's response to pain: role of temperament and parental characteristics, Pediatrics. 87 (1991) 171-177.

[31] R.Y. Zisk, M. Grey, J.E. MacLaren, Z.N. Kain, Exploring sociodemographic and personality characteristic predictors of parental pain perceptions, Anesth. Analg. 104 (2007) 790-798. doi:10.1213/01.ane.0000257927.35206.c1.

[32] C. Spielberger, R. Gorsuch, R. Lushene, State-trait anxiety inventory manual, Consulting Psychologists Press, Palo Alto, CA, 1970.

[33] S. Miller, Monitoring and blunting: Validation of a questionnaire to assess styles of information seeking under threat, J. Pers. Soc. Psychol. 52 (1987) 345-353.

[34] E. Whitley, J. Ball, Statistics review 6: Nonparametric methods., Crit. Care. 6 (2002) 50913. http://www.ncbi.nlm.nih.gov/pubmed/12493072 (accessed July 3, 2016).

[35] M. Cepeda, J. Africano, R. Polo, R. Alcala, D. Carr, What decline in pain intensity is meaningful to patients with acute pain?, Pain. 105 (2003) 151-7. http://www.ncbi.nlm.nih.gov/pubmed/14499431.

[36] J. Farrar, J. Berlin, B. Strom, Clinically important changes in acute pain outcome measures: a validation study., J. Pain Symptom Manage. 25 (2003) 406-11. http://www.ncbi.nlm.nih.gov/pubmed/12727037. 
[37] R.Y. Zisk Rony, M.A. Fortier, J.M. Chorney, D. Perret, Z.N. Kain, Parental postoperative pain management: attitudes, assessment, and management, Pediatrics. 125 (2010) e1372-

[38] C. Vincent, M. Chiappetta, A. Beach, C. Kiolbasa, K. Latta, R. Maloney, L.S. Van

[39] Z.N. Kain, M.A. Fortier, J.M. Chorney, L. Mayes, Web-based tailored intervention for preparation of parents and children for outpatient surgery (WebTIPS): development., Anesth. Analg. 120 (2015) 905-14. doi:10.1213/ANE.0000000000000610.

[40] M.A. Fortier, E. Bunzli, J. Walthall, E. Olshansky, H. Saadat, R. Santistevan, L. Mayes, Z.N. Kain, Web-Based Tailored Intervention for Preparation of Parents and Children for Outpatient Surgery (WebTIPS): Formative Evaluation, Anesth. Analg. 120 (2015) 915922. doi:10.1213/ANE.0000000000000632.

[41] American Academy of Pediatrics. Committee on Drugs., Acetaminophen toxicity in children., Pediatrics. 108 (2001) 1020-4. http://www.ncbi.nlm.nih.gov/pubmed/11581462 (accessed July 14, 2016).

[42] C.A. Prows, X. Zhang, M.M. Huth, K. Zhang, S.N. Saldaña, N.M. Daraiseh, H.R. Esslinger, E. Freeman, J.H. Greinwald, L.J. Martin, S. Sadhasivam, Codeine-related adverse drug reactions in children following tonsillectomy: a prospective study., Laryngoscope. 124 (2014) 1242-50. doi:10.1002/lary.24455.

[43] R. Bushra, N. Aslam, An overview of clinical pharmacology of Ibuprofen., Oman Med. J. 25 (2010) 155-1661. doi:10.5001/omj.2010.49.

[44] M. Eriksson, U. Nilsson, A.C. Bramhagen, E. Idvall, E. Ericsson, Self-reported 
postoperative recovery in children after tonsillectomy compared to tonsillotomy, Int. J. Pediatr. Otorhinolaryngol. (2017). doi:10.1016/j.ijporl.2017.02.029. measures after tonsil surgery: an analysis of 32,225 children from the National Tonsil Surgery Register in Sweden 2009-2016, Eur. Arch. Oto-Rhino-Laryngology. (2017). doi:10.1007/s00405-017-4679-4.

509

510 
511 Table 1. Pain medication instructions provided by each hospital site for parents to manage their

\section{2 child's postoperative pain}

\begin{tabular}{|c|c|}
\hline Site & Instructions \\
\hline $\begin{array}{l}\text { CHOC - Children's } \\
\text { Hospital Orange County }\end{array}$ & $\begin{array}{l}\text { Administer acetaminophen and ibuprofen as recommended on label packaging and } \\
\text { alternate between acetaminophen and ibuprofen for pain relief. }\end{array}$ \\
\hline $\begin{array}{l}\text { CHLA - Children's } \\
\text { Hospital Los Angeles }\end{array}$ & $\begin{array}{l}\text { All parents were advised to administer acetaminophen every } 4 \text { hours as needed for pain. } \\
\text { Parents of older children were allowed to administer Tylenol with codeine, per } \\
\text { prescription from the surgeon (this practice was stopped in 2012). Children were not } \\
\text { allowed aspirin or aspirin-containing medications within two weeks of surgery. }\end{array}$ \\
\hline $\begin{array}{c}\text { LPCH - Lucile Packard } \\
\text { Children's Hospital at } \\
\text { Stanford }\end{array}$ & $\begin{array}{l}\text { Younger Children: For at least the first two postoperative days and nights, administer } \\
\text { alternating acetaminophen and ibuprofen every 4-6 hours. Specifically, administer } \\
\text { acetaminophen, then, in 4-6 hours, administer ibuprofen, and in another 4-6 hours, } \\
\text { administer acetaminophen. Parents should wake their children at night to continue } \\
\text { medication, at least for the first few nights. In a few days postoperatively, parents may } \\
\text { increase time between doses depending on child pain level. } \\
\text { Older Children: Parents may administer Oxycodone to older children every } 6 \text { hours } \\
\text { postoperatively, in addition to alternating acetaminophen and ibuprofen regimen noted } \\
\text { above. } \\
\text { All Children: Parents should offer children 1-2 ounces of liquid to drink during all } \\
\text { waking hours to prevent dehydration. }\end{array}$ \\
\hline $\begin{array}{l}\text { The Children's Hospital, } \\
\text { Denver }\end{array}$ & $\begin{array}{l}\text { Most frequently, parents were advised to administer acetaminophen every } 4 \text { hours as } \\
\text { needed and ibuprofen every } 6 \text { hours as needed. At the discretion of the particular } \\
\text { surgeon performing the operation, some parents were also instructed to administer } \\
\text { Oxycodone every } 6 \text { hours as needed in addition to the acetaminophen and ibuprofen. }\end{array}$ \\
\hline
\end{tabular}

513 Note: Instructions represents the practice during the years data in this manuscript was collected.

514 Important Note: In 2013, the FDA released a black box warning for the use of codeine in children $<12$ years of age,

515 as it may cause serious complications such as respiratory depression and death. In 2018, the FDA issued a 
516 "Contraindication" to codeine in children $<12$ years old, and a "Warning" against its use in adolescents ages 12-18

517 who are obese or may have respiratory problems such as obstructive sleep apnea or severe lung disease. 
518 Table 2. Demographic Characteristics of Respondents $(n=311)$. Categorical variables reported as

519 counts and proportions. Continuous variables reported as mean \pm standard deviation.

\begin{tabular}{|c|c|}
\hline Variable & Study Population \\
\hline \multicolumn{2}{|l|}{ Child's Gender } \\
\hline Male & $156(50.2 \%)$ \\
\hline Female & $154(49.5 \%)$ \\
\hline Missing & $1(0.3 \%)$ \\
\hline Child's Age (years) & $6 \pm 3$ \\
\hline \multicolumn{2}{|l|}{ Parent Respondent } \\
\hline Mother & $265(85.2 \%)$ \\
\hline Father & $40(12.9 \%)$ \\
\hline Other/Missing & $6(1.9 \%)$ \\
\hline \multicolumn{2}{|l|}{ Parent Language } \\
\hline English & $230(74.0 \%)$ \\
\hline Spanish & $81(26.0 \%)$ \\
\hline \multicolumn{2}{|l|}{ Parent Marital Status } \\
\hline Single & $36(11.6 \%)$ \\
\hline Married & $218(70.1 \%)$ \\
\hline Other/Missing & $74(23.8 \%)$ \\
\hline \multicolumn{2}{|l|}{ Parent Education } \\
\hline$<12$ Years & $45(15.0 \%)$ \\
\hline Graduated High School & $68(21.9 \%)$ \\
\hline Some College & $43(13.8 \%)$ \\
\hline College/Professional & $133(44.3 \%)$ \\
\hline Missing/Prefer not to answer & $22(7.3 \%)$ \\
\hline \multicolumn{2}{|l|}{ Income Bracket (Dollars) } \\
\hline 20,000 and under & $61(19.6 \%)$ \\
\hline
\end{tabular}




\section{1,000-50,000}

$51,000-100,000$

101,000 and greater

Missing/Prefer not to answer

\section{Child Race/Ethnicity}

White

Hispanic

Asian

Other/Prefer not to answer

Has child had previous surgery?

Yes

No

Missing
$73(23.5 \%)$

$51(23.5 \%)$

$76(24.5 \%)$

$50(16.7 \%)$

$113(36.3 \%)$

$149(47.9 \%)$

$22(7.1 \%)$

$27(9.0 \%)$

$63(20.3 \%)$

$239(76.8 \%)$

$9(2.9 \%)$ 
521 Table 3. Parent-child pain rating agreement using Wilcoxon Signed Rank Test. Parent NRS

522 (pNRS) and Child FPS (cFPS) scores are reported by median (range, 25\%-75\%).

523

\begin{tabular}{|c|c|c|c|c|c|}
\hline & \multirow[b]{2}{*}{$\mathbf{n}$} & \multirow[b]{2}{*}{$\begin{array}{l}\text { Parent } \\
\text { pNRS }\end{array}$} & \multicolumn{3}{|c|}{$\begin{array}{l}\text { Difference Between Median } \\
\text { Parent and Child Pain Rating }\end{array}$} \\
\hline & & & $\begin{array}{l}\text { Child } \\
\text { cFPS }\end{array}$ & $\begin{array}{l}\text { Parent-Child } \\
\text { (pNRS - cFPS) }\end{array}$ & $p$ \\
\hline Day 1 & 306 & $6(3-8)$ & $4(2-8)$ & +2 & $<.0001$ \\
\hline Day 2 & 287 & $5(3-7)$ & $4(2-6)$ & +1 & $<.0001$ \\
\hline Day 3 & 203 & $4(2-6)$ & $2(0-2)$ & +2 & $<.0001$ \\
\hline
\end{tabular}

524 
525 Table 4. Analyses by chi-square (for categorical variables) and one-way ANOVA (for

526 continuous variables) to identify any potential predictors of group differences between

527 Underestimator Dyads (UE), Agreement Dyads (A), and Overestimator Dyads (OE). Categorical

528 variables are reported as percentages of total and continuous variables are reported as median

529 (interquartile range).

\begin{tabular}{|c|c|c|c|c|}
\hline Predictor Variable & $\mathrm{UE}(\mathrm{n}=16)$ & $A(n=182)$ & OE $(n=57)$ & $\mathbf{p}$ \\
\hline \multicolumn{5}{|l|}{ Child } \\
\hline Child Gender (Male) & $50.0 \%$ & $50.0 \%$ & $49.1 \%$ & 0.993 \\
\hline Child Race-Ethnicity & 43.8\% (Hispanic) & $51.1 \%$ (Hispanic) & $49.1 \%$ (White) & 0.556 \\
\hline Child Age & $8(6)$ & $6(3)$ & $5(3)$ & 0.108 \\
\hline Previous Surgery (No) & $68.8 \%$ & $80.8 \%$ & $77.8 \%$ & 0.496 \\
\hline Anxiety at Previous Med Visits & $11.0(36)$ & $25.5(43)$ & $14(23)$ & $0.012 *$ \\
\hline Site & & & & $0.005^{*}$ \\
\hline Children's Hospital Orange County & $1(2.4 \%)$ & $34(80.9 \%)$ & $7(16.7 \%)$ & \\
\hline Children's Hospital Los Angeles & $5(8.5 \%)$ & $48(81.3 \%)$ & $6(10.2 \%)$ & \\
\hline Lucille Packard Children's Hospital & $6(9.8 \%)$ & $32(52.5 \%)$ & $23(37.7 \%)$ & \\
\hline Children's Hospital, Denver & $4(4.3 \%)$ & $68(73.1 \%)$ & $21(22.6 \%)$ & \\
\hline EAS - Emotionality & $2.5(1)$ & $2.8(1)$ & $2.8(1)$ & 0.596 \\
\hline EAS - Shyness & $2.2(1)$ & $2.4(1)$ & $2.6(1)$ & 0.491 \\
\hline EAS - Activity & $4.6(1)$ & $4.2(1)$ & $4.2(1)$ & 0.802 \\
\hline EAS - Sociability & $4.0(1)$ & $3.8(1)$ & $3.8(1)$ & 0.932 \\
\hline \multicolumn{5}{|l|}{ Parent } \\
\hline Education (College or Professional Degree) & $56.3 \%$ & $42.4 \%$ & $54.7 \%$ & 0.917 \\
\hline Race-Ethnicity & $56.3 \%$ (White) & 48.9\% (Hispanic) & $54.5 \%$ (White) & 0.421 \\
\hline Language (English) & $62.5 \%$ & $64.6 \%$ & $80.7 \%$ & 0.592 \\
\hline Marital Status (Married) & $68.8 \%$ & $75.3 \%$ & $75.4 \%$ & 0.236 \\
\hline
\end{tabular}




\begin{tabular}{|c|c|c|c|c|}
\hline Country Parent Grew Up In (USA) & $81.3 \%$ & $58.8 \%$ & $57.9 \%$ & 0.166 \\
\hline Pain level that parent expects child to & $60.0(23)$ & $61.0(28)$ & $55.0(20)$ & 0.542 \\
\hline \multicolumn{5}{|l|}{ experience during surgery $(0-100)$} \\
\hline MAQ - Avoidance & $24.0(13)$ & $26.0(15)$ & $22.0(12)$ & 0.713 \\
\hline MAQ - Side Effects & $21.0(7)$ & $22.0(5)$ & $21.0(6)$ & 0.104 \\
\hline MAQ - Appropriate Usage & $22.0(7)$ & $20.0(7)$ & $20.0(4)$ & 0.536 \\
\hline STAI - State & $36.2(10)$ & $40.0(13)$ & $38.0(10)$ & 0.924 \\
\hline STAI - Trait & $37.0(10)$ & $35.5(10)$ & $34.0(13)$ & 0.897 \\
\hline Miller Behavioral Style - Monitoring & $7.0(4)$ & $7.0(5)$ & $8.0(4)$ & 0.866 \\
\hline Miller Behavioral Style - Blunting & $2.0(2)$ & $3.0(2)$ & $3.0(3)$ & 0.389 \\
\hline
\end{tabular}

$530 \quad$ Note: * indicates significance at $p<0.05$.

531 
532 Table 5. Number of dyads in each (Underestimators, Agreement, and Overestimators) by

533 hospital site on each of the three postoperative days.

534

\begin{tabular}{|c|c|c|c|c|}
\hline Hospital Site & & UE & $\mathbf{A}$ & $\overline{\mathbf{O E}}$ \\
\hline \multirow[t]{3}{*}{ Children's Hospital Orange County } & Day 1 & $2(4.8 \%)$ & $33(82.5 \%)$ & $7(16.7 \%)$ \\
\hline & Day 2 & $3(7.3 \%)$ & $32(78.0 \%)$ & $6(14.7 \%)$ \\
\hline & Day 3 & $1(3.3 \%)$ & $26(86.7 \%)$ & $3(10.0 \%)$ \\
\hline \multirow[t]{3}{*}{ Children's Hospital Los Angeles } & Day 1 & $9(15.5 \%)$ & $40(69.0 \%)$ & $9(15.5 \%)$ \\
\hline & Day 2 & $6(10.1 \%)$ & $46(78.0 \%)$ & $7(11.9 \%)$ \\
\hline & Day 3 & $3(6.7 \%)$ & $34(75.5 \%)$ & $8(17.8 \%)$ \\
\hline \multirow[t]{3}{*}{ Lucille Packard Children's Hospital } & Day 1 & $7(11.5 \%)$ & $35(57.4 \%)$ & $19(31.1 \%)$ \\
\hline & Day 2 & $6(9.8 \%)$ & $30(49.2 \%)$ & $25(41.0 \%)$ \\
\hline & Day 3 & $4(11.4 \%)$ & $21(60.0 \%)$ & $10(28.6 \%)$ \\
\hline \multirow[t]{3}{*}{ Children's Hospital, Denver } & Day 1 & $4(4.4 \%)$ & $65(71.4 \%)$ & $22(24.2 \%)$ \\
\hline & Day 2 & $7(7.7 \%)$ & $61(67.0 \%)$ & $23(25.3 \%)$ \\
\hline & Day 3 & $3(3.4 \%)$ & $58(65.9 \%)$ & $27(30.7 \%)$ \\
\hline
\end{tabular}


535 Table 6. Summary of Logistic Regression Analysis to examine the effect of demographic and

536 clinical variables on likelihood of parents over and under-estimating their child's postoperative

537 pain as compared to parent-child dyads in agreement.

538

539

540

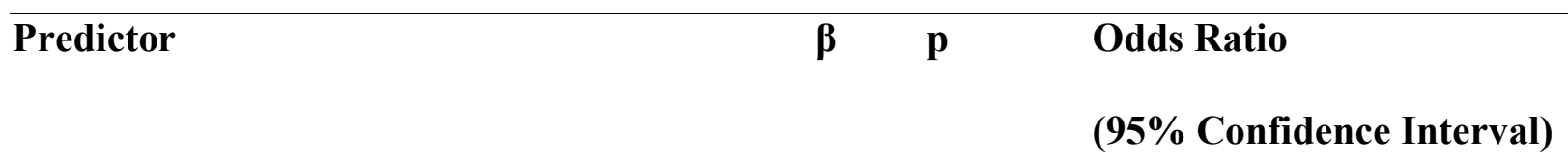

Underestimators

Site (Lucille Packard Children's Hospital)

Children's Hospital, Denver

Children's Hospital Orange County

Children's Hospital Los Angeles

\begin{tabular}{l|l|l} 
& 0.210 & \\
-1.159 & 0.088 & $0.314(0.083-1.190)$ \\
-1.852 & 0.095 & $0.157(0.018-1.376)$ \\
-0.588 & 0.364 & $0.556(0.156-1.975)$
\end{tabular}

Overestimators

541 Note: $*$ indicates significance at $p<0.05$. 
543 Table 7. Socioeconomic status of dyads grouped into either the Underestimator, Agreement, or

544 Overestimator at each hospital site, as represented by parent respondent level of education and

545 total family income.

\begin{tabular}{lcccc}
\hline Socioeconomic Measures & $\begin{array}{c}\text { Children's Hospital } \\
\text { Orange County }\end{array}$ & $\begin{array}{c}\text { Children's Hospital } \\
\text { Los Angeles }\end{array}$ & $\begin{array}{c}\text { Lucille Packard } \\
\text { Children's Hospital }\end{array}$ & $\begin{array}{c}\text { Children's Hospital, } \\
\text { Denver }\end{array}$ \\
\hline $\begin{array}{l}\text { Income } \\
20,000 \text { and under }\end{array}$ & $12(30.9 \%)$ & $19(32.2 \%)$ & $9(14.8 \%)$ & $9(9.7 \%)$ \\
21,000 to 50,000 & $12(28.6 \%)$ & $6(6.2 \%)$ & $20(32.8 \%)$ & $14(15.1 \%)$ \\
51,000 to 100,000 & $7(16.7 \%)$ & $7(11.9 \%)$ & $11(18.0 \%)$ & $25(26.9 \%)$ \\
101,000 and greater & $3(7.1 \%)$ & $15(25.5 \%)$ & $12(19.7 \%)$ & $37(39.8 \%)$ \\
Missing/No answer & $7(16.6 \%)$ & $12(20.3 \%)$ & $17(27.9 \%)$ & $8(8.6 \%)$ \\
Parent Education & & & & $5(5.4 \%)$ \\
$<12$ Years & $6(14.2 \%)$ & $8(13.6 \%)$ & $14(45.0 \%)$ & $20(21.5 \%)$ \\
Graduated High School & $14(33.3 \%)$ & $9(15.3 \%)$ & $13(21.3 \%)$ & $12(12.9 \%)$ \\
Some College & $11(26.2 \%)$ & $7(11.9 \%)$ & $6(9.8 \%)$ & $52(55.9 \%)$ \\
College/Professional & $8(19.1 \%)$ & $28(47.4 \%)$ & $23(37.7 \%)$ & $6(6.5 \%)$ \\
Missing/No answer & $3(7.2 \%)$ & $7(11.9 \%)$ & $5(8.2 \%)$ & \\
\hline
\end{tabular}


547 Fig. I: Parent-Child Dyads in Agreement vs. Disagreement by pNRS and cFPS 548

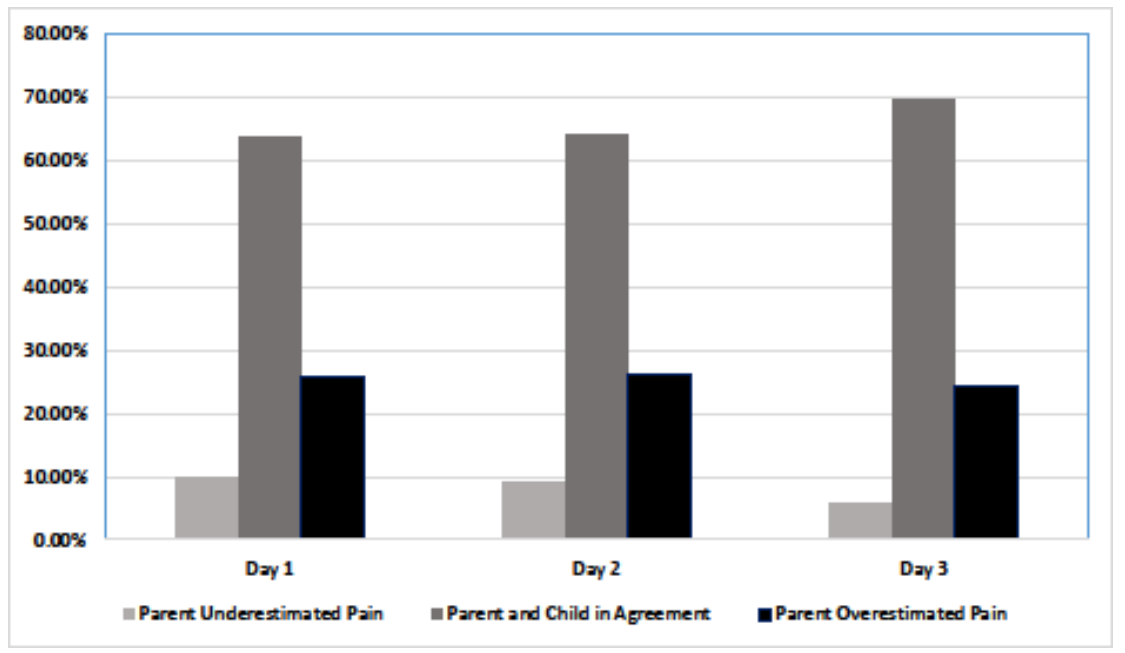

